\title{
Prevalence of multidrug-resistant Klebsiella pneumoniae strains isolated from patients with cardiovascular disease
}

\author{
Otilia Banu ${ }^{1}$, Coralia Bleotu², Manuela Burtea ${ }^{3}$, Ilda Czobor ${ }^{4}$, Irina Gheorghe ${ }^{4}$, Iuliana Porumbel ${ }^{4}$, \\ Mariana Carmen Chifiriuc ${ }^{4}$
}

Corresponding author:

Coralia Bleotu, MD

Institute of Virology Stefan S.

Nicolau, Bucharest, Romania

E-mail: cbleotu@yahoo.com
"“Prof. Dr. C.C. lliescu” Emergency Institute of Cardiovascular Diseases, Bucharest, Romania ${ }^{2}$ Institute of Virology Stefan S. Nicolau, Bucharest, Romania

${ }^{3}$ Medical Center Matei Basarab Bucharest, Romania

${ }^{4}$ Faculty of Biology, University of Bucharest, Research Institute of the University of Bucharest, Romania

\section{ABSTRACT}

Klebsiella spp. are common Gram-negative pathogens, frequently encountered in nosocomial infections. The production of antibiotic-inactivating enzymes, such as ESBL(extended-spectrum beta-lactamases) and carbapenemases associated with multidrug-resistant (MDR) phenotypes are increasingly reported in the last decade, leading to very limited therapeutic options of the produced infections. The purpose of this study was to high light the antibiotic profile of Klebsiella spp. strains isolated from clinical samples in patients with cardiovascular disease.

Materials and Methods: A number of 256 Klebsiella strains isolated from different clinical specimens were analysed for the antimicrobial susceptibility profiles testing by disk - diffusion and Vitek2 automated system. ESBL production was confirmed by the double disk test and carbapene mases producing by the modified Hodge test and E-tests.

Results: Out of the 256 isolated strains, multi-drug resistance (cephalosporins/aminoglycosides/quinolones) was encountered in $149(58 \%)$ strains. A number of $53(21 \%)$ strains were ESBL producers and $96(38 \%)$ were resistant to carbapenems, out of which, 41 (43\%) were carbapene mase positive.

Conclusion: Due to the extremely low therapeutic alternatives in case of infections produced by MDR strains rapid identification of colonized or infected patients and screening of carriers, together with the routine detection of ESBL and carbapenemases by standard methods is highly recommended to be available in every clinical laboratory, to achieve effective antibiotic resistance management policies.

Key words: antibiotic susceptibility profile, ESBL, MDR, carbapenemases, double disk test, Modified Hodge test, E-test

\section{INTRODUCTION}

Klebsiella is one of the most common Gram-negative pathogens, frequently encountered in nosocomial infections (1-4). Klebsiella spp. are known as a cause of community-acquired pneumonia, in particular associated with chronic 
alcoholism, with a high mortality rate, especially in the absence of adequate treatment (5). As an opportunistic pathogen, Klebsiella spp. occurs in patients with diabetes mellitus or chronic obstructive pulmonary disease.

MDR strains are a major problem in nosocomial infections management (6), and moreover, similar resistance profiles were found in Klebsiella spp. strains isolated from community infections (7). One of the universally recognized major reasons involved in the development of MDR is the widely misused antibiotic therapy (8). The prevalence of resistance due to ESBL production was also recently reported, invery rapid growth (9). ESBL sare enzymes that mediate resistance to third and fourth generation cephalosporins (GIII, GIV) and monobactams but do not affect susceptibility to cefamicine and carbapenems. ESBLs belong to the $2 \mathrm{~b}$ of the 2 class after Bush, Jacoby and Medeiros classification schema, and to class $A$ in Ambler molecular classification (10). ESBL production is plasmid mediated, and could easily be transferred in Enterobacteriaceae group, leading to the accumulation of resistance genes in strains containing multidrugresistance plasmids (15-19). ESBL-producing microorganisms often contain determinants of resistance to aminoglycosides and fluoroquinolones and therefore treatment options are drastically limited (20-26).

Carbapenemases are beta-lactamases capable of hydrolyzing penicillins, cephalosporins, carbapenems and monobactam, being included in $A$, Band $D$ of the Ambler molecular classification. Such enzymes producing bacteria cause severe infections in which betalactams are in effective (11-14). The purpose of this study was to detect the prevalence of ESBL and carbapenemases producing Klebsiella spp. strains in patients of cardiology clinics.

\section{MATERIALS AND METHODS}

There were studied 256 Klebsiella spp. strains collected from different biological specimens i.e.: urine, blood, respiratory tract secretions, wound and soft tissue secretions and prosthetic devices, over atenmonth period (from January 2014 to November 2014). Out of the 256 strains, 86 were isolated from urine, 68 from wounds, 72 from respiratory tract secretions, 21 from blood and 9 from prosthetic devices infections. Identification to species level was based on biochemical characteristics using chromogenic media: Chromatic Mueller Hinton (MH Chromatic), chromID ESBL, chromID Carba, Api2OE and Vitek2 Compact System. Antibiotic susceptibility testing was done by the Kirby Bauer - disc diffusion method and automatic Vitek II system (MIC), according CLSI standard 2014 (27-37). Isolates resistant to cefotaxime orceftriaxone, were further subjected to confirmatory test by double disk method and/or E-test, for ESBL production. We used the following discs: cefotaxime $(30 \mu \mathrm{g})$, piperacillintazobactam (100 $\mu \mathrm{g} / 10 \mu \mathrm{g})$, ceftazidime (30 $\mu \mathrm{g})$, and ceftazidime-clavulanic acid (30 $\mu \mathrm{g} / 10 \mu \mathrm{g}$ ). After incubating the platesat $37^{\circ} \mathrm{C}$, for $16-20 \mathrm{~h}$ in an aerobic atmosphere, there were observedand measured the diameters of growth inhibition zones around the disks. An increase of inhibition zone diameter with $\geq 5 \mathrm{~mm}$ for each antimicrobial agent tested in combination with clavulanic acid, versus inhibition agent zone testalone, confirmed the ESBL production in the studied strains (figure 1).
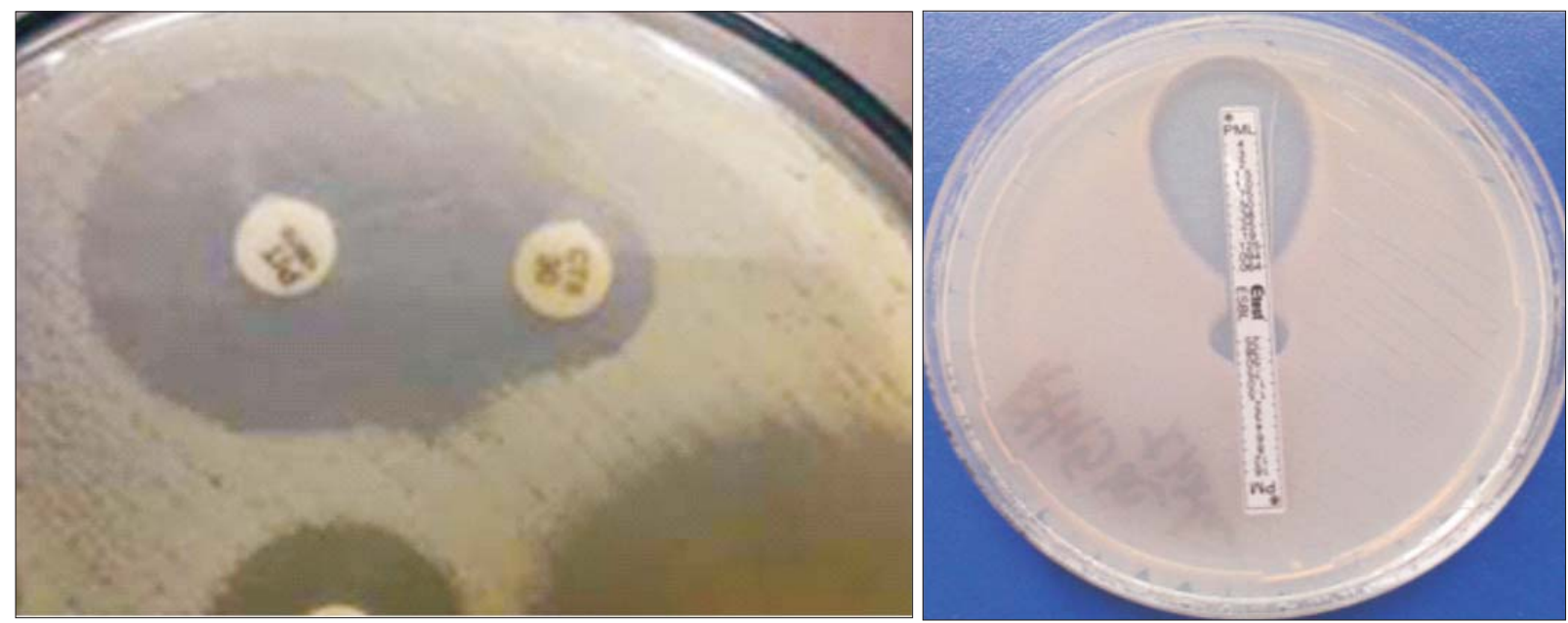

Figure 1 - ESBL production using double disk (left) and E-test (right) 

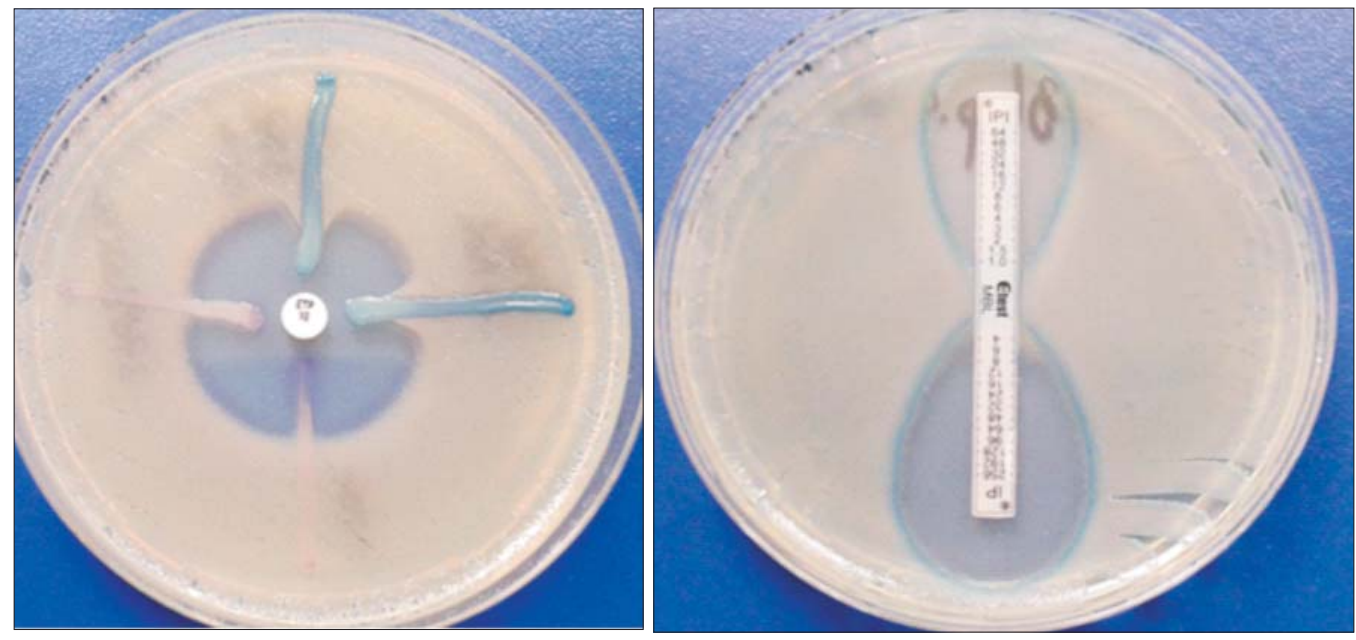

Figure 2 - Carbapenemases production using Chromatic MH: Modified Hodge test (left), E-test MBL (right)

Phenotypic detection of carbapenemases producing strains was made for all isolates showing a decreased susceptibility to carbapenems revealed by diskdiffusion method. Modified Hodge test revealed that the strains with low susceptibility to carbapenems are producing carbapenemases. E-test was used for detection of MBL-producing strains teston Chromatic $\mathrm{MH}$ medium (figure 2).

\section{RESULTS}

Out of the 256 Klebsiella spp. strains, 252 were Klebsiella pneumoniae subsp. pneumoniae and 4 were Klebsiella oxytoca.

Antibiotic susceptibility profile: 43 strains were susceptible to all tested antibiotics excepting ampicillin, which belongs to the natural resistance phenotypes of these species. The prevalence of antibiotic resistance was: cefazolin - $85 \%$, cefuroxime - $82 \%$, cefotaxime $73 \%$, cefepime - $70 \%$ gentamicin - $60 \%$, amikacin - $25 \%$, ciprofloxacin - 74\%, nitrofurantoin - 48\%, trimethorim / sulphametoxazole - $78 \%$, piperacillin-tazobactam - 70\%, ertapenem - 56\%, imipenem - $49 \%$, and meropenem $49 \%$ (figure 3).

ESBL production was highlighted in 53 strains (21\%), out of which, 14 strains (26\%) were isolated from urine, $14(26 \%)$ from respiratory tract secretions, $20(38 \%)$ from wound secretions, 3 (6\%) from blood and 2 (4\%) from prosthetic devices associated infections (figure 4).

Carbapenemases production was highlighted in96 strains (38\%) showing carbapenems resistance phenotypes to imipenem and meropenem. All 96 MDR strains were tested for carbapenemases production using the modified Hodge test. From these, 41 strains (16\%) were Hodge positive, of which 15 were isolated collected from urine, 11 from respiratory tract secretions, 10

\section{K. pneumoniae}

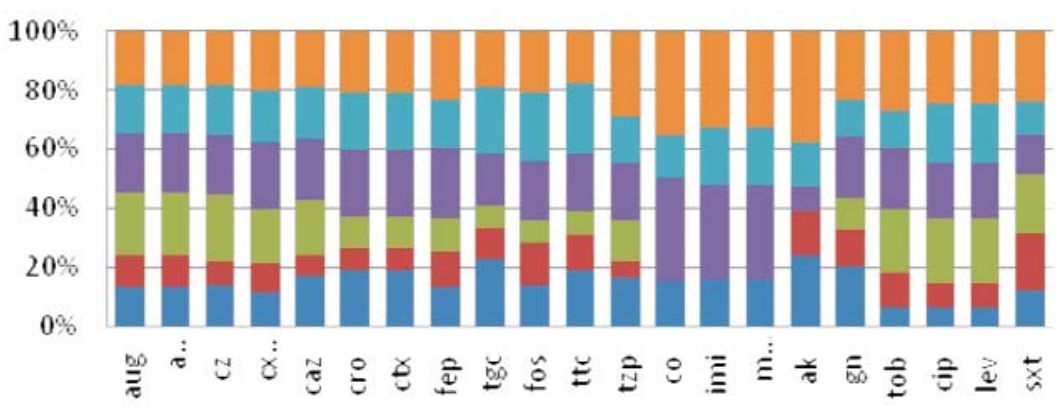

urine

wond

secretion

- tracheal

secretions

prosthetic

devices

sputum

blood

Figure 3 - Prevalence of antibiotic resistance phenotypes in Klebsiella spp. strains 


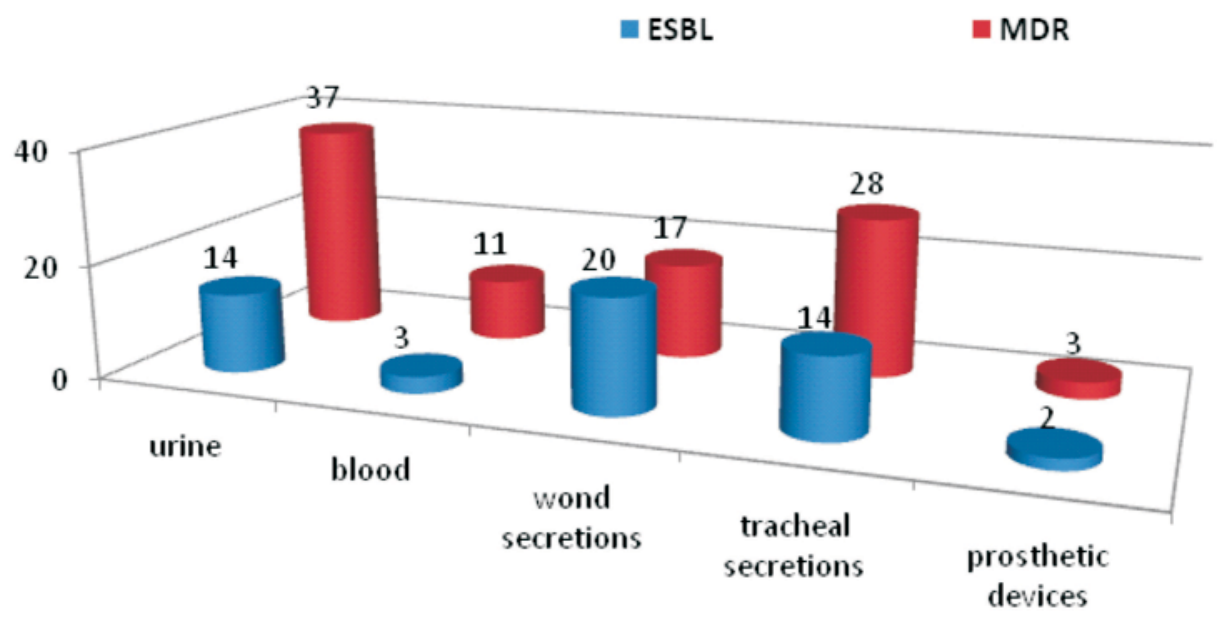

Figure 4 - Prevalence of ESBL phenotypes in Klebsiella spp. strains

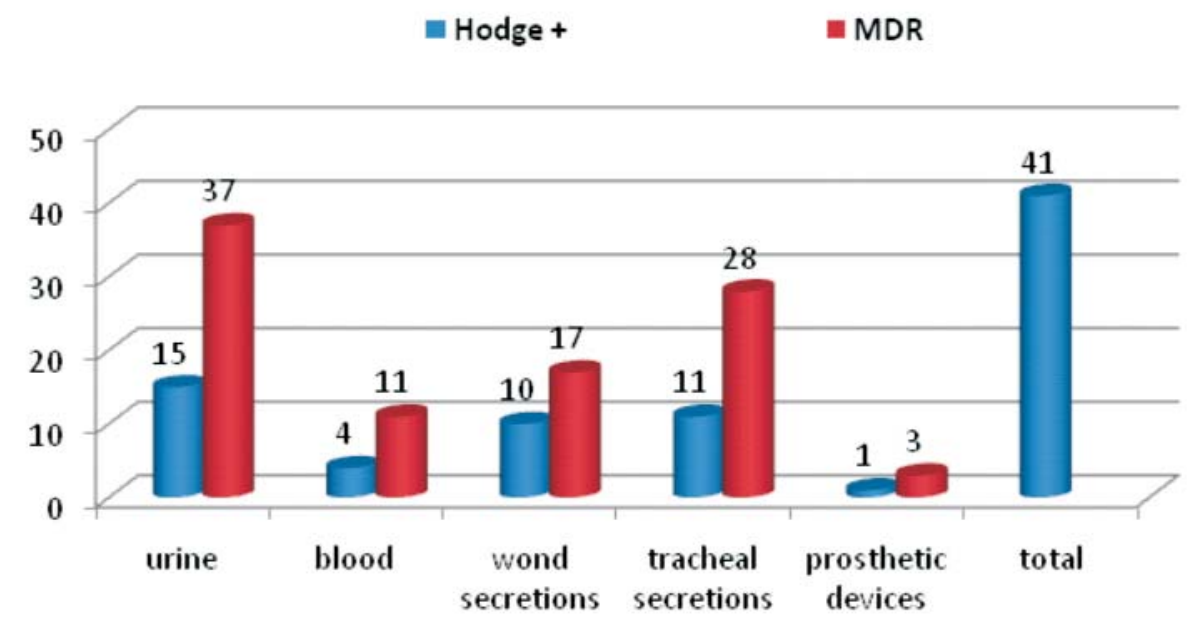

Figure 5 - Prevalence of carbapenemases producing $K$. pneumoniae strains established by the modified Hodge test

from wound secretions, 4 from blood and 1 from prosthetic devices associated infections (figure 5).

\section{DISCUSSIONS}

Klebsiella pneumoniae is the most common pathogen isolated from ICU and the most common species of carbapenem producing Enterobacteriaceae. The type of carbapenemase - producing Enterobacteriaceae depends of the country and may be associated with historical/cultural relationships and exchange of populations with other countries with high prevalence. The future trend of these carbapenemase producing Enterobacteriaceae epidemics will be an increasing one, as the reservoir of cabapenemase producers are growing worldwide. Cross- border transfer of patients, travel, medical tourism and refugees might also play an important role. Another important aspect of the genus Klebsiella is the rapid emergence of MDR strains that often leads to treatment failure, with dramatic consequences especially for immuno-suppressed patients.

Empiric antibacterial therapy without a secure background provided by laboratory assays, often leads not only to the emergence of antibiotic resistance but also to an increasing incidence of the mortality rate. Therefore, routine laboratory detection of ESBL and carbapenemases producing strains by standard methods is highly recommended to be available in every clinical lab, because carbapenemases production 
in Enterobacteriaceae are mostly plasmid-encoded, which largely explain their common association with other resistance markers and their multidrug resistance patterns.

The increasing prevalence of infections with Klebsiella spp. was observed in patients aged between 20 and 65 years. Only 43 strains (17\%) showed susceptibility to all tested antibiotics. Among the resistant strains, the highest resistance rates were recorded for the first generation cephalosporins (cefazolin - 85\%) and second generation cephalosporins (cefuroxime $82 \%)$, followed by third generation cephalosporins (cefotaxime - 73\%) and piperacillin- tazobactam (70\%). An increased rate of resistance was also observed for aminoglycosides (60\%) and quinolones (74\%). The strains exhibiting the ESBL phenotype were isolated with the highest rates in wound secretions $(38 \%)$, followed by urine $(26 \%)$, respiratory tract secretions $(26 \%)$, blood (6\%) and prosthetic devices associated infections (4\%).

In this study, 10 patients were infected with MDR Klebsiella spp. strains, which were sensitive only to colistin and polymixin B. These strains were identified as Klebsiella pneumoniae subsp. pneumoniae with one exception, i.e. $K$. oxytoca isolated from an urinary tract infection of acatheterized diabetic patient. These patients were treated with colistin (iv), and supportive therapy, but 6 of the 10 patients died. The dead patients were aged between 40 and 80 years and harboured polymicrobial infections with multiresistant strains and sepsis before exitus. Other bacterial species isolated from these patients except Klebsiella pneumoniae were Staphylococcus aureus, Serratia marcescens and Pseudomonas aeruginosa. The cause of death may be multifactorial, because none of these patients had Klebsiella pneumoniae bacteremia.

\section{CONCLUSIONS}

Although important nosocomial outbreaks with carbapenemase - producing Enterobacteriaceae have been often reported in our country, many cases were imported from other hospital units from the country and from abroad. Although dissemination of these strains mainly occurs among hospitalized patients, community acquisition is also increasing. The present study highlights the high prevalence of MDR Klebsiella spp. strains (38\%), mainly Klebsiella pneumoniae subsp. pneumoniae in our hospital setting, being associated with limited therapeutic options and a high mortality rate.

These results underline the necessity for readily available methods for the rapid identification of colonized or infected patients and screening of carriers must in every laboratory, contributing to a better surveillance of resistance transfer and spreading and to the optimization of the therapeutic strategies.

\section{Acknowledgements}

"This work received financial support through the project entitled "CERO - Career profile: Romanian Researcher", grant number POSDRU/159/1.5/S/135760, cofinanced by the European Social Fund for -Sectorial Operational Programme Human Resources Development 2007-2013".

\section{REFERENCES}

1. Podschun R, Ullmann U. Klebsiella spp. as nosocomial pathogens: epidemiology, taxonomy, typing methods, and pathogenicity factors. Clin Microbiol Rev. 1998 0ct;11(4):589-603.

2. Jakab Z. Prevention of health-care-associated infections (HCAl) and antimicrobial resistance (AMR) in Europe. V International Conference on Patient Safety, Healthcare Associated Infection and Antimicrobial Resistance, Madrid, Spain; availablefrom:http:/www.euro.who.int/_data/assets/ pdf_file/0006/113829/Patient_safety_pres_jakab.pdf, 2010.

3. ECDC. Antimicrobial resistance and healthcare-associated infections (AMR/HCAl). Annual epidemiological report; Reporting on 2009 surveillance data and 2010 epidemic intelligence data; available from: www. ecdc.europa.eu. 2011.

4. Popescu GA, Popescu C, Gavriliu LC, Miftode E, Rugina S, Nicoara E. Rezultatele unui studiu de supraveghere a rezistentei la antibiotice în câteva spitale de boli infectioase - MAR-T. Infectio.ro 2010; 24(4):34-39.

5. Kwak YG, Choi SH, Choo EJ, Chung JW, Jeong JY, Kim NJ, et al. Risk factors for the acquisition of carbapenem resistant Klebsiella pneumoniae among hospitalized patients. Microb Drug Resist. 2005; 11(2):165-169.

6. Lemmen SW, Häfner H, Zolldann D, Stanzel S, Lótticken R. Distribution of multi-resistant Gram-negative versus Gram-positive bacteria in the hospital inanimate environment. J Hosp Infect. 2004 Mar;56(3):191-7.

7. Buehlmann M, Fankhauser $\mathrm{H}$, Laffer R, Bregenzer T, Widmer AF. The inguinal skin: an important site of colonization with extended spectrumbetalactamase-producing Enterobacteriaceae. Infect Control Hosp Epidemiol. 2010 Apr;31(4):427-8. doi: 10.1086/651309.

8. Souli M, Galani I, Giamarellou H.Emergence of extensively drug-resistant and pandrug-resistant Gram-negative bacilli in Europe. Eurosurveillance 2008;13(47). Availablefrom: http://www.eurosurveillance.org ViewArticle. aspx? Articleld $=19045$

9. Thomson KS. Extended-spectrum-beta-lactamase, AmpC, and carbapenemase issues. J Clin Microbiol. 2010 Apr;48(4):1019-25. doi: 10.1128/ JCM.00219-10. Epub 2010 Feb 24

10. Bush K, Jacoby GA.Updated functional classification of beta-lactamases. Antimicrob Agents Chemother. 2010 Mar;54(3):969-76. doi: 10.1128/ AAC.01009-09.

11. Cornaglia G, Akova M, Amicosante G, Canton R, Cauda R, Docquier JD, et al.Metallo-beta-lactamases as emerging resistance determinants in Gramnegative pathogens: open issues.Int J Antimicrob Agents. 2007 Apr;29(4): 380-8.

12. Pasteran F, Mendez T, Guerriero L, Rapoport M, Corso A.Sensitive screening tests for suspected class $A$ carbapenemase production in species of Enterobacteriaceae. J ClinMicrobiol. 2009 Jun;47(6):1631-9. doi: 10.1128/ JCM.00130-09.

13. Queenan AM, Bush K.Carbapenemases: the versatile beta-lactamases. ClinMicrobiol Rev. 2007 Jul;20(3):440-58.

14. Potron A, Kalpoe J, Poirel L, Nordmann P. European dissemination of a single OXA-48-producing Klebsiella pneumoniae clone. ClinMicrobiol Infect. 2011 Dec;17(12):E24-6. doi: 10.1111/j.1469-0691.2011.03669.x.

15. Kristinsson KG, Monnet DL. Increasing multidrug resistance and limited 
treatment options: situation and initiatives in Europe. Eurosurveillance; 13(47). Availablefrom: http://www.eurosurveillance.org/ViewArticle.aspx? Articleld =19043, 2008.

16. Weisenberg SA, Morgan DJ, Espinal-Witter R, Larone HD. Clinical outcomes of patients with KPC-producing Klebsiella pneumoniae following treatment with imipenem or meropenem. Diagn Microbiol Infect Dis. 2009 Jun;64(2):233-5. doi: 10.1016/.j.diagmicrobio.2009.02.004.

17. Kuti JL, Dandekar PK, Nightingale CH, Nicolau DP.Use of Monte Carlo simulation to design an optimized pharmacodynamic dosing strategy for meropenem. J ClinPharmacol. 2003 0ct;43(10):1116-23.

18. Falagas ME, Rafailidis PI, Ioannidou E, Alexiou VG, Matthaiou DK, Karageorgopoulos DE, et al. Colistin therapy for microbiologically documented multidrug-resistant Gram-negative bacterial infections: a retrospective cohort study of 258 patients.Int J Antimicrob Agents. 2010 Feb;35(2):194-9. doi: 10.1016/.jijantimicag.2009.10.005.

19. Endimiani A, Patel G, Hujer KM, Swaminathan M, Perez F, Rice LB, et al. In vitro activity of fosfomycin against blaKPCcontaining Klebsiella pneumoniae isolates, including those nonsusceptible to tigecycline and/or colistin. Antimicrob Agents Chemother. 2010 Jan; 54(1):526-9. doi: 10.1128/ AAC.01235-09.

20. Borer A, Saidel-Odes L, Riesenberg K, Eskira S, Peled N, Nativ R, et al. Attributable mortality rate for carbapenem resistant Klebsiella pneumonia bacteremia. Infect Control Hosp Epidemiol. 2009 0ct;30(10):972-6. doi: 10.1086/605922

21. Falagas ME, Karageorgopoulos DE, Nordmann P.Therapeutic options for infections with Enterobacteriaceae producing carbapenemhydrolyzing enzymes. Future Microbiol. 2011 Jun;6(6):653-66. doi: 10.2217/ fmb.11.49.

22. Samonis G, Maraki S, Karageorgopoulos DE, Vouloumanou EK, Falagas ME. Synergy of fosfomycin with carbapenems, colistin, netilmicin, and tigecycline against multidrug-resistant Klebsiella pneumoniae, Escherichia coli, and Pseudomonas aeruginosa clinical isolates. Eur J ClinMicrobiol Infect Dis. 2012 May;31(5):695-701. doi: 10.1007/s10096-011-1360-5.

23. Livermore DM, Warner M, Mushtaq S, Doumith M, Zhang J, Woodford N. What remains against carbapenem-resistant Enterobacteriaceae? Evaluation of chloramphenicol, ciprofloxacin, colistin, fosfomycin, minocycline, nitrofurantoin, temocillin and tigecycline.Int $\mathrm{J}$ Antimicrob Agents. 2011 May;37(5):415-9. doi: 10.1016/j.jiantimicag.2011.01.012.

24. Tzouvelekis LS, Markogiannakis A, Psichogiou M, Tassios PT, Daikos GL. Carbapenemases in Klebsiella pneumoniae and other Enterobacteriaceae: an Evolving Crisis of Global Dimensions, ClinMicrobiol Rev. 2012 Oct; 25(4):682-707. doi: 10.1128/CMR.05035-11.

25. Andrasevic AT, Dowzicky MJ. In vitro activity of tigecycline and comparators against Gram-negative pathogens isolated from blood in Europe (20042009).Int J Antimicrob Agents. 2012 Feb;39(2):115-23. doi: 10.1016/ j.jiantimicag.2011.10.010.

26. Dziekan G. Global strategies for antimicrobial resistance prevention and control. Congress of the InternationalFederation of Infection Control, Vilnius 2009; available from:http://www. ficic2009.com/default.asp

27. Landman D, Salvani JK, Bratu S, Quale J. Evaluation of techniques for detection of carbapenem-resistant Klebsiella pneumoniae in stool surveillance cultures. J Clin Microbiol. 2005 Nov;43(11):5639-41.

28. Thomson KS, Robledo IE, Vazquez GJ, Moland ES. KPC screening by updated BD Phoenix and Vitek 2 automated systems. J Clin Microbiol. 2011 Sep;49(9):3386-7. doi: 10.1128/JCM.00772-11

29. Tsakris A, Poulou A, Themeli-Digalaki K, Voulgari E, Pittaras T, Sofianou D, et al.Use of boronic acid disk tests to detect extendedspectrum beta -lactamases in clinical isolates of KPC carbapenemase possessing Enterobacteriaceae. J Clin Microbiol. 2009 Nov;47(11):3420-6. doi: 10.1128/JCM.01314-09.

30. Kim S-Y, Hong SG, Moland ES, Thomson KS. Convenient test using a combination of chelating agents for detection of metallo-beta-lactamases in the clinical laboratory. J Clin Microbiol. 2007 Sep;45(9):2798-801.

31. Miriagou V, Cornaglia G, Edelstein M, Galani I, Giske CG, Gniadkowski M, et al. Acquired carbapenemases in Gram-negative bacterial pathogens: detection and surveillance issues. Clin Microbiol Infect. 2010 Feb;16(2): 112-22. doi: 10.1111/j.1469-0691.2009.03116.X.

32. Lee K, Kim CK, Yong D, Jeong SH, Yum JH, Seo YH, et al.Improved performance of the modified Hodge test with MacConkey agar for screening carbapenemase-producing Gramnegative bacilli. J Microbiol Methods. 2010 Nov;83(2):149-52. doi: 10.1016/j.mimet.2010.08.010.

33. Cohen Stuart J, Leverstein-Van Hall MA; Dutch Working Party on the Detection of Highly Resistant Microorganisms.Guideline for phenotypic screening and confirmation of carbapenemases in Enterobacteriaceae. Int J Antimicrob Agents. 2010 Sep; 36(3):205-10. doi: 10.1016/j.jiantimicag. 2010.05.014.

34. Pasteran F, Lucero C, Soloaga R, Rapoport M, Corso A. Can we use imipenem and meropenemVitek 2 MICs for detection of suspected KPC and other carbapenemase producers among species of Enterobacteriaceae?J Clin Microbiol. 2011 Feb;49(2):697-701. doi: 10.1128/JCM.01178-10.

35. Patel G, Bonomo RA.Status report on carbapenemases: challenges and prospects. Expert Rev Anti Infect Ther. 2011 May;9(5):555-70. doi: 10.1586/eri.11.28.

36. Clinical and Laboratory Standards Institute (CLSI) Performance standards for antimicrobial susceptibility testing. M100-S20. CLSI, Wayne, PA, USA, 2014.

37. Garrec H, Rouzet LD, Golmard JL, Jarlier V, Robert J. Comparison of nine phenotypic methods for detection of extended-spectrum-beta-lactamase production by Enterobacteriaceae. J Clin Microbiol. 2011 Mar;49(3):104857. doi: $10.1128 / J C M .02130-10$ 